\title{
Overlap of temporal niches among four sympatric species of shrews
}

\section{Leszek RYCHLIK}

Rychlik L. 2005. Overlap of temporal niches among four sympatric species of shrews. Acta Theriologica 00: 000-000.

Hypotheses about the dependence of circadian activity from metabolic rate and the segregation of temporal niches among competing species were verified by the study of activity patterns in a shrew community of two semiaquatic species, Neomys anomalus Cabrera, 1907 and N. fodiens (Pennant, 1771), and two terrestrial species, Sorex araneus Linnaeus, 1758 and S. minutus Linnaeus, 1766, co-existing in wet habitats of Białowieża Forest (E Poland). In ten trapping sessions, performed in early summer between 1991 and 2000, traps were open 24 hours continuously and patrolled at 1:00, 5:00, 10:00, 15:00, and 20:00. All the shrew species were most active between 20:00 and 1:00, and least active around mid-day (10:00-15:00). However, activity of the two Sorex species was lower than that of the two Neomys species in the period 20:00-1:00, but higher in the period 15:00-20:00. Both Neomys species displayed clearly nocturnal, unimodal patterns of activity. In contrast, activity of both Sorex species was relatively evenly distributed over 24 hours and they increased their activity earlier (ie after 15:00) than both Neomys species (after 20:00). These results confirm the idea that small shrew species with higher metabolic rate have more frequent and more equally distributed activity bouts than large species. Overlap of temporal niches was the highest within genera (99.29\% between both Neomys species and 98.36\% between both Sorex species), the lowest between $N$. fodiens and S. araneus $(88.26 \%)$ and S. minutus $(89.34 \%)$, and intermediate between N. anomalus and both Sorex species (91.78 and 93.34\%, respectively). Such high interspecific overlaps suggest a joint-action of other mechanisms that separate ecological niches of these species also in other dimensions (eg food, microhabitat).

Mammal Research Institute, Polish Academy of Sciences, Waszkiewicza 1, 17-230

Białowieża, Poland; lrychlik@bison.zbs.bialowieza.pl

Keywords: Neomys, Sorex, circadian activity, niche separation, interspecific competition

Running title: Temporal niches of sympatric shrews 


\section{Introduction}

There is still a need to investigate mechanisms of interspecific competition for a better understanding of evolutionary processes and co-existence of different species. Separation of temporal niches is one of the most important mechanisms diminishing competition and allowing coexistence of ecologically similar species of mammals (Schoener 1974, Halle 2000a). Among small mammals, separation of temporal niches was proved among many rodent species (Buchalczyk 1964, Kenagy 1973, O’Farrell 1974, Cameron et al. 1979, Kotler et al. 1993, Priotto and Polop 1997, Kronfeld-Schor and Dayan 1999, Halle 2000a, b, Ziv and Smallwood 2000).

When investigating the circadian activity of shrews, most authors focused their attention on metabolic level and food requirements or occasionally on home range usage related to these factors (eg Churchfield 1990, Merritt and Vessey 2000). Usually, individual animals or single species have been studied. Indeed, the circadian activity of some common species of shrews is well known, as for example, of European Sorex araneus or North American Blarina brevicauda. In contrast, activity patterns of many uncommon species remain poorly investigated or unknown.

Another problem is that shrew activity was more frequently analysed under laboratory conditions (where it can be distorted) than in the wild, and especially rare were comparative studies of several species performed in the field (Merritt and Vessey 2000). Little attention has been paid to the fact that differences in circadian activity can be an efficient mechanism diminishing interspecific competition and partitioning resources, and thus that activity patterns of particular species, composing a given shrew community, can (at least partly) result from interspecific competition.

Although habitat and food are usually more important than time in separation of ecological niches, there are communities where differentiation of activity phases is the most important (Schoener 1974, Halle 2000a). However, because of high metabolic rates and energetic needs, shrews display polyphasic activity rhythms, so it is generally very difficult to identify interspecific differences in their activity time (Cawthorn 1994, Taylor 1998, Castién and Gosálbez 1999, Merritt and Vessey 2000). In consequence, there is no evidence (from the field or laboratory) showing that circadian activity of shrews is influenced by interspecific competition (Merritt and Vessey 2000). Therefore, Castién and Gosálbez (1999) suggest that shrew temporal niches are not separated, and conclude that differences in microhabitat use are the primary factors enabling the coexistence of shrews.

In the present study, the shrew community of four species coexisting in wet habitats was analysed. The shrew community included two semiaquatic species, Neomys anomalus Cabrera, 1907 and N. fodiens (Pennant, 1771), and two terrestrial species, Sorex araneus 
Linnaeus, 1758 and S. minutus Linnaeus, 1766. Thus potentially, a clear separation of habitat niches could be expected. However, Rychlik (2000) found high interspecific overlaps in macrohabitat (91.4-98.7\%) and microhabitat selection (82.8-95.7\%) in this community. On the other hand, overlaps in dietary composition were also high among these species (62.7$87.7 \%$ ), with the exception of $N$. fodiens and S. minutus (44.4\%; S. Churchfield and L. Rychlik, unpubl.). Furthermore, these species are usually very aggressive during interspecific encounters, especially by food and shelters (Krushinska and Pucek 1989, Krushinska and Rychlik 1993, L. Rychlik and R. Zwolak, unpubl.). All this suggests that these shrews compete for food, space or shelters. Indeed, competitive release has been recently demonstrated (Rychlik et al. 2004): experimental introduction or removal of the dominant $N$. fodiens caused shifts in habitat selection and circadian activity of $N$. anomalus. In accordance with this, in Portugal (where $N$. fodiens does not occur), $N$. anomalus lived directly at water edge (Rychlik and Ramalhinho 2005) - the microhabitat occupied by N. fodiens in other regions of Europe. Therefore, competition among these species should be diminished by some mechanisms to enable their stable co-existence, and Rychlik (2000) hypothesised that differences in activity rhythms could contribute to a separation of their ecological niches.

Thus, the aims of the present field investigations were: (1) To describe patterns of circadian activity of the four shrew species in the community under natural conditions. These species differ considerably in body masses, metabolic rates and food requirements (Vogel 1976, Taylor 1998, Rychlik and Jancewicz 2002). Energy reserves in adipose tissue are relatively larger in large species than small ones (Hanski 1985). In consequence, starvation time of large shrews is much longer than in small shrews; for example, it is 1.6 times longer in Sorex araneus than S. minutus (Hanski 1994). Therefore, small shrew species were expected to have a higher activity level, with activity bouts more equally distributed between day and night and less pronounced activity peaks. (2) To verify the hypothesis about segregation of temporal niches among the four species. Since the shrews are ordered, according to behavioural domination, from the largest $N$. fodiens to the smallest $S$. minutus (L. Rychlik and R. Zwolak, unpubl.), activity peaks of the dominant $N$. fodiens within an optimal period (early night) and shifts of subordinate species peaks to earlier or later hours were predicted.

\section{Material and methods}

Study area

The study area (in size $80 \times 70 \mathrm{~m}, 5600 \mathrm{~m}^{2}$ ) was localised in the valley of Narewka river in forest compartment 426 of the Białowieża Forest (E Poland). The area included three 
macrohabitats: tussock-sedge swamp (Caricetum appropinquatae from alliance Magnocaricion), streamside alder-ash forest (Circaeo-Alnetum from alliance Alno-Padion according to Faliński 1986) and the ecotone between them. A stream crossed through the plot. See Rychlik (2000, 2001) for more details on the study area.

Trapping procedure

Between 1991 and 2000, 10 trapping sessions were performed. These lasted from 5 to 12 days (mean 8.4 days, median 10 days). Activity of small mammals is strongly influenced by photoperiod and season (Cameron et al. 1979, Churchfield 1982, 1990, DeCoursey 1989, 1990, Halle and Stenseth 2000, Merritt and Vessey 2000). To avoid these influences, all trapping sessions took place between 17 June and 31 July, so the duration of day-time ranged only between $16 \mathrm{hr} 0$ ' and $16 \mathrm{hr} 46^{\prime}$ (mean $16 \mathrm{hr} 27^{\prime}$, median $16 \mathrm{hr} 30.5^{\prime}$ ). The study area was covered with 180 trapping points distributed in a grid $5 \times 5 \mathrm{~m}$ (15 rows of 12 traps each). In all trapping sessions one wooden box live-trap (Polish construction; L16.5 $\times$ W7.5 $\times \mathrm{H} 9.5 \mathrm{~cm}$, entrance W4 $\times$ H5 cm, with vertically closing door after an animal steps on a movable floorpart) was set per trapping point. In three 5-day sessions, a metal-cone pitfall ( $40 \mathrm{~cm}$ deep, $16 \mathrm{~cm}$ of opening diameter) was added at each point. Minced meat was put into the pitfalls but no bait was put into the box traps (to obtain uncontaminated samples of faeces for another study). Traps were continuously open 24 hours and patrolled at 1:00, 5:00, 10:00, 15:00, and 20:00. All trapped animals were released at the point of capture immediately after recording their species. See Rychlik (2000, 2001) for more details on methods.

\section{Data analysis}

Since the 1:00-5:00 trap-check interval was shorter than the other intervals (4 vs $5 \mathrm{hr}$ ), for each species and each trapping session the number of shrew captures in this interval was multiplied by 1.25 to avoid underestimation. Particular trapping sessions differed with regard to the duration, number of traps set and number of shrews captured. Therefore, in order to standardise the results from each trapping session, the numbers of captures were converted into percentages, with the total number of captures of a given species during a given session being $100 \%$. Next, the percentage values for a given time-interval were averaged for the ten sessions and the obtained averages are shown in Fig. 1. During one 5-day session (July 1991) no pygmy shrews were captured, so this session was rejected and the sample size, used in statistical analyses, was 9 for $S$. minutus (10 for the three other species). 
Intraspecific changes in activity were analysed with the Wilcoxon Signed Ranks and chi-square tests, whereas interspecific differences in activity rhythms were analysed with the Pearson's correlation, Kruskal-Wallis test and Mann-Whitney $U$-test (GraphPAD InStat 1.13, 1990, SYSTAT 5.01, 1992). For multiple pairwise comparisons, the Bonferroni corrections were applied: the significance level was $p<0.005$ for Wilcoxon test and $p<0.0083$ for Mann-Whitney $U$-test; for the other statistical analyses: $p<0.05$. Interspecific overlaps of temporal niches were estimated according to the formula of Pianka (1973) but expressed in percentages:

$$
\alpha_{i j}=\left\{\left(\Sigma p_{i a} \cdot p_{j a}\right) \cdot\left[\left(\Sigma p_{i a}^{2}\right) \cdot\left(\Sigma p_{j a}{ }^{2}\right)\right]^{-0.5}\right\} \cdot 100 \%
$$

where $\alpha_{i j}$ is the overlap of temporal niches between species $i$ and $j, p_{i a}$ is a proportion of activity during the period $a$ in total activity of species $i$, and $p_{j a}$ is a proportion of activity during the period $a$ in total activity of species $j$.

\section{Results}

In total, 1620 captures (including recaptures) of shrews were recorded. These included: 192 captures of $N$. anomalus, 518 of $N$. fodiens, 720 of $S$. araneus, and $190 \mathrm{of} S$. minutus.

Peak activity of $N$. anomalus occurred between 20:00 and 1:00 (Fig. 1). Its activity was then much higher than in the four remaining periods and in comparison to the periods 10:00-15:00 and 15:00-20:00 the differences reached the level of statistical significance determined by the Bonferroni correction (Wilcoxon test: $Z=-2.803, p=0.005$ for both comparisons). The lowest activity of $N$. anomalus was registered in the period 10:00-15:00. It was then 7 times lower than in the period 20:00-1:00 and 3 times lower than in the period 1:00-5:00. Such a distribution of activity during the five distinguished periods was very significantly deviated from an uniform distribution $\left(\chi^{2}=54.5, \mathrm{df}=4, p<<0.001\right)$.

Activity rhythm of $N$. fodiens was very similar: between 20:00 and 1:00 its activity was much higher than in the four other periods (except in comparison with the period 1:005:00, the differences reached the level of statistical significance: $Z=-2.803, p=0.005$ ). Between 10:00 a 15:00 activity of $N$. fodiens was the lowest: almost 10 times lower than in the period 20:00-1:00 and over 4 times lower than in the period 1:00-5:00. Moreover, its activity between 1:00 and 5:00 was 2.4 times higher than in the period 5:00-10:00 and 3 times higher than in the period 15:00-20:00. This distribution of activity was extremely different 
from an uniform distribution $\left(\chi^{2}=78.7, \mathrm{df}=4, p<<0.001\right)$. Thus, both species of water shrews displayed clearly nocturnal, unimodal (ie with one peak) patterns of activity.

In $S$. araneus activity rhythm was little differentiated during the 24 -hr-period. The highest activity of this species was also observed in the period 20:00-1:00, but it was only 2.4 times higher than the lowest activity between 10:00 and 15:00 and less than 2 times higher in comparison to the period 5:00-10:00. None of comparisons between distinguished periods showed significant differences in the activity of $S$. araneus. And overall, the distribution of activity did not differ from an uniform distribution $\left(\chi^{2}=8.9, \mathrm{df}=4, p>0.05\right)$.

The activity rhythm of $S$. minutus was more differentiated than that of $S$. araneus (Fig. $1)$, but it was less different from an uniform distribution $\left(\chi^{2}=16.3, \mathrm{df}=4, p=0.005\right)$ than in both Neomys species. S. minutus was most active between 20:00 and 1:00 and least active between 10:00 and 15:00. Its activity during the period 10:00-15:00 was 5.5 times lower than in the period 20:00-1:00 and 3.5-4 times lower than in the three other periods (however, all these differences were insignificant).

The highest significant correlation between activity patterns was found for $N$. fodiens and $N$. anomalus (Table 1) - this means that generally these two species did not differ in diel activity. A lower but still significant correlation (ie similarity) occurred between $S$. araneus and S. minutus. In contrast, activity patterns of Sorex species differed from the two Neomys species (insignificant correlations).

More detailed interspecific comparisons of circadian activity revealed significant differences in the periods 20:00-1:00 (Kruskal-Wallis test: $H=15.385, \mathrm{df}=3, p=0.002$ ) and 15:00-20:00 $(H=8.588, \mathrm{df}=3, p=0.035)$ (Fig. 1). In the period 20:00-1:00, Sorex species were less active than Neomys species. Significant differences were found between $S$. araneus and $N$. anomalus (Mann-Whitney test: $U=12.0, p<0.005)$ as well as $N$. fodiens $(U=6.0, p=$ 0.001). In contrast, in the period 15:00-20:00, the two Sorex species were more active than the Neomys shrews (significant difference between $S$. araneus and $N$. fodiens: $U=12.0, p=0.005$ ). This also means that Sorex species increased their activity earlier (ie after 15:00) than Neomys species (after 20:00).

In contrast to my prediction, overlap of temporal niches was high (Table 1). It was the highest within genera (99.29\% between both Neomys species and $98.36 \%$ between both Sorex species), the lowest between $N$. fodiens and both Sorex species, and intermediate between $N$. anomalus and the Sorex species. 


\section{Discussion}

Infrequent trap checking (every 4-5 hr) is a disadvantage of this study as shorter fluctuations in circadian activity of shrews may have been undetected. However, the applied regime of trap checking was similar for example to Voesenek and van Bemmel's study (1984), while Pernetta (1977) analysed shrew activity in only three 8-hr periods. Nevertheless, in future studies of shrew activity patterns, a "higher resolution" would surely be better.

Sorex araneus and many other shrews spend a considerable proportion of their activity under the ground surface, burrowing in litter and soil (Churchfield 1990, Ellenbroek and Hamburger 1991, Ohdachi 1997). The pitfalls and especially box traps used in this study were inappropriate to detect such an activity. However, the study area was so marshy that extensive burrowing was unlikely. Therefore, in my opinion, inability to trap shrews underground did not underestimate the total activity of potential burrowers.

Another problem was that the study area was inhabited by many rodent species and some of them (Clethrionomys glareolus and Microtus oeconomus) were numerous and frequently captured (Rychlik 2000, 2001), blocking many traps. In consequence, some shrews could not be captured, and thus their activity may have been underestimated to a certain degree during peak activity of rodents. M. oeconomus was captured mainly in the morning (10:00), Apodemus agrarius in the evening (20:00) and A. flavicollis at night (1:00). However, captures of the most numerous C. glareolus as well as all rodent species considered together were rather equally distributed during day and night (L. Rychlik, unpubl.). Therefore, it can be accepted that this factor influenced activity indices of all shrew species and trapping periods in a similar way.

An advantage of this study is that it was carried out in the field under natural conditions, and that the whole community of four shrew species was covered. Moreover, ten trapping sessions performed over 10 years allowed to reduce a possible variability in circadian activity resulting from differences between years in climatic conditions, population densities of shrews and other small mammals, pressure of predators, etc. Additionally, the trapping sessions were performed always in the same short period (the turn of June and July), hence the influence of changes in photoperiod on shrew activity was eliminated. In some field studies, data on shrew activity were collected only during daylight hours (eg Shillito 1963, Cawthorn 1994, Ivanter and Makarov 2002). Therefore, it is important that, in the present study, trapping was carried out for 24 hours continuously because this allowed full information on the circadian activity of shrews to be obtained. 
There are many published data on shrew activity obtained in laboratory. However, the natural activity rhythms were usually changed by laboratory conditions (artificial photoperiod, constant temperature, feeding regime, etc) - for example, feeding time clearly influenced shrew activity cycles (Buchalczyk 1972). Another problem is that shrews were usually kept individually in cages, so they were not engaged in intra- or interspecific interactions. Meanwhile, it was found that shrews kept with conspecifics were more active than those kept singly (Goulden and Meester 1978, Barnard et al. 1983). In the field, the activity of shrews undergoes natural conditions and is surely influenced by interactions with different animals. Therefore, I will compare my results to other field data rather than to laboratory findings.

Activity patterns of particular shrew species

In the present study, a clear nocturnal, unimodal pattern of summer circadian activity was found for N. anomalus, and this is a new finding. This species is still poorly investigated in many aspects and its circadian activity was almost unknown so far. The existing data are contradictory: N. anomalus was mainly nocturnal (Buchalczyk 1972) or diurnal (Bäumler 1975), but the sample sizes were very small.

Neomys fodiens also displayed a nocturnal, unimodal pattern of activity in the present study. This finding is similar to the results of Jánský and Hanák (1960), and especially Voesenek and van Bemmel (1984) who trapped most individuals of $N$. fodiens during the night. In contrast, Churchfield (1984) captured ca 77\% individuals of $N$. fodiens during the day. In Switzerland, $N$. fodiens was equally active during the day and night (Lardet 1988). However, Lardet gives only averages for all radioactive tracking sessions performed between April and December. Since proportions of diurnal and nocturnal activity of shrews changes between seasons (Buchalczyk 1972, Churchfield 1984), it is possible that summer nocturnal activity of Lardet's water shrews was masked by data from other seasons.

In the present work, activity of $S$. araneus was relatively evenly distributed over 24 hours and thus can be classified as a cathemeral (ie all hours) pattern. Such a pattern has been reported 3 times for this species, whereas a nocturnal pattern, with one or two activity peaks, has been found 10 times (Merritt and Vessey 2000). In Germany (Bäumler 1975; trapping), S. araneus was active in all hours, with two slight increases of activity around sunrise and sunset. In the Czech Republic (Jánský and Hanák 1960) and the Netherlands (Voesenek and van Bemmel 1984), S. araneus was nocturnal with a clear peak of activity (between 21:00 and 0:00 and between sunset and 2:00, respectively). In Russia (Karulin et al. 1974; radioactive tracking), distances travelled by common shrews were, on average, 6 times longer during night than at day. Also 
in England (Pernetta 1977, Churchfield 1984; trapping), S. araneus was more active during the night, but activity peaks were not determined. A distinctly different activity cycle was found in France (Yalden et al. 1973; trapping): S. araneus was more active during the day than night, with the main activity peak after sunrise (between 5:00 and 10:00). It is difficult to explain this inverse pattern.

Data on activity patterns of $S$. minutus are very poor. In summer in the Czech Republic (Jánský and Hanák 1960), this species was much more active during the night than day, with a peak activity between 21:00 and 0:00 and very low activity between 9:00 and 18:00. In England (Pernetta 1977), S. minutus displayed very high activity between 16:00 and 0:00, low between 8:00 and 16:00, and intermediate from 0:00 to 8:00. The author suggested that in the period 16:00-0:00 much of the activity could occur during the daylight, but this remains unknown because of a low, 8-hour accuracy of Pernetta's study.

This survey of literature data on shrew activity patterns shows a great intraspecific variety. This variety may result from: (1) a high interindividual variability in circadian activity, as was stressed by Buchalczyk (1972); (2) differences in photoperiodic, climatic and environmental conditions, as well as temporal changes in prey availability in different regions of Europe; (3) short study periods (usually 1 or 2 years), which would influence the results through fluctuations in the factors mentioned in point 2; and (4) different composition and densities of shrew communities as well as other co-existing small mammals.

\section{Interspecific differences}

Shrews differ in metabolic rates and food requirements: these are significantly higher (per unit of body mass) in Sorex than Neomys species (Vogel 1976, 1980, Hanski 1984, Taylor 1998, Rychlik and Jancewicz 2002). Moreover, larger shrews are able to have longer breaks in feeding than small ones because they are able to accumulate more energy in their bodies (Hanski 1985, 1994). Thus, it was expected that smaller Sorex shrews would forage more frequently than larger Neomys species and would not break their activity during the day.

In the present study, the two Neomys species displayed clearly nocturnal, unimodal patterns of activity, whereas the activity of both Sorex species was relatively evenly distributed over 24 hours. Sorex species also increased their activity earlier than Neomys species. Since $N$. fodiens (body mass ca $15 \mathrm{~g}$ ) and N. anomalus (10 g) were considerably larger than S. araneus (8 g) and $S$. minutus ( $3 \mathrm{~g}$ ), these results support the idea and predictions mentioned above. It can be accepted, therefore, that the energy reserves stored in the bodies of water shrews were high enough to allow them to wait over the unfavourable period of daylight hours (when, for example, a risk 
from birds of prey is high) and forage intensively under optimal conditions of darkness. Sorex species were not able to behave in this way.

Surprisingly, there are no previous field data supporting these findings and the above interpretation obtained on the same shrew species. Laboratory evidence is also scarce. Tupikova (1949) found that $S$. minutus was the species most active during the day, $N$. fodiens was the least and $S$. araneus intermediate, while the activity of all three species was similar during the night. Buchalczyk (1972) obtained data on activity of all the four species in winter but not in summer. In winter, feeding activity (ie number of visits to the feeding box) was high in $S$. minutus, medium in $S$. araneus and low in $N$. fodiens, which is consistent with the prediction. However, feeding activity of $N$. anomalus was much higher than in S. minutus. This could be explained by a very high mobility of $N$. anomalus (Krushinska and Pucek 1989, Krushinska and Rychlik 1993, Zwolak and Rychlik 2004).

More supporting results come from laboratory investigations of other shrew communities. In Buckner's study (1964), the smallest shrews (Microsorex hoyi-3.5 g, and Sorex cinereus - $3.6 \mathrm{~g}$ ) displayed the highest mass-specific metabolic rate, highest activity level, and highest proportion of diurnal activity. The largest Blarina brevicauda $(20.1 \mathrm{~g})$ showed the lowest metabolic rate, activity level, and proportion of diurnal activity, whereas these measures were intermediate in S. arcticus weighting $5.4 \mathrm{~g}$ (Buckner 1964). Yoshino and Abe (1984) found that larger Sorex unguiculatus was generally less active and displayed one clear peak of activity from late night till sunrise (3:00-5:00), whereas smaller $S$. caecutiens was more active and its increased activity lasted from 20:00 to 6:00 (ie almost throughout the whole night). In agreement with these findings, the largest $S$. unguiculatus was able to have long breaks in activity, $S$. caecutiens broke its activity for medium periods and the smallest $S$. gracillimus only for short periods (Ohdachi 1994). Moreover, S. gracillimus displayed many short activity bouts during the day, whereas the two other species were rarely active during the day (Ohdachi 1994).

Overlap of temporal niches

A high interspecific and especially intergeneric overlap of temporal niches was found in this study. This is inconsistent with my predictions. However, Jánský and Hanák (1960) also showed very similar activity patterns of $S$. araneus and $S$. minutus in summer, with activity peaks between 21:00 and 0:00 in both species. The activity peak of $N$. fodiens seemed to occur later (3:00-6:00) but their data set for this species was too small to credit such a statement. In the Netherlands, both $S$. araneus and $N$. fodiens displayed peaks of activity between sunset and 
2:00 (Voesenek and van Bemmel 1984). But unlikely to my results, Dutch N. fodiens was more active than $S$. araneus during the day, whereas $S$. araneus was more active in the night. In contrast to the results described above, certain differentiation of temporal niches was also found. In winter, $N$. fodiens was most active just after sunrise (around 9:00), S. minutus was the most active species about 11:00, S. araneus displayed peak activity at sunset (between 15:00 and 17:00), and N. anomalus displayed a most pronounced peak in the night (from 19:00 to 23:00) and very low activity in the day (Buchalczyk 1972). In spring, the peak activity of $N$. fodiens occurred just before sunrise (3:00-5:00), S. minutus remained the species most active during the day, whereas $S$. araneus was nocturnal with increased activity from 21:00 till 3:00 (Buchalczyk 1972). In summer, $S$. minutus was more active than $S$. araneus between 16:00 and 0:00 (Pernetta 1977). N. fodiens was much more active during day than night, whereas S. araneus behaved conversely (Churchfield 1984). Concerning other shrew communities, the activity peak of $S$. caecutiens was recorded between 0:00 and 3:00, whereas in S. unguiculatus it occurred later (3:00-5:00; Yoshino and Abe 1984). Also, some differences in activity among three Crocidura species from South Africa were found: peak activity of $C$. mariquensis occurred just before sunrise, main activity peak of $C$. hirta was recorded just after sunset, and $C$. flavescens displayed two peaks, after sunset and at sunrise (Baxter et al. 1979).

High interspecific overlaps, found in the present study, suggest that other mechanisms separate the ecological niches of these species. As was shown (Rychlik 2000), macrohabitat segregation had little effect on this separation. Differentiation of microhabitat preferences contribute to a greater degree, but interspecific overlaps were still high (>75\%; Rychlik 2000). Overlap in dietary composition was also considerable (usually $>60 \%$; S. Churchfield and L. Rychlik, unpubl.). Thus one can conclude that availability of food and/or other resources is so high in wet habitats of Białowieża Forest that competition among the four species is weak and they can co-exist with relatively high overlaps in different niche dimensions. However, the recent experiments (Rychlik et al. 2004 and in prep.) and studies of allopatric populations (Malmquist 1985, 1986, Rácz and Demeter 1998, Rychlik and Ramalhinho 2005) suggest that the competition, especially intrageneric, is not weak. Therefore, I conclude that these species can coexist due to the sum of small differences in all niche dimensions rather than to a big difference in a certain dimension. If so, this situation can be described as the joint-action of different separation mechanisms. Differences in body size and foraging modes (Rychlik 1997, Rychlik and Jancewicz 2002, S. Churchfield and L. Rychlik, unpubl.) as well as behavioural mechanisms of conflict avoidance (L. Rychlik and R. Zwolak, unpubl.) diminish this competition as well. 
The obtained results did not support the prediction on shifts of activity peaks. However, the hypothesis about certain segregation of temporal niches cannot be rejected until the activity of these species will be investigated with a more detailed procedure, such as trapping with more frequent trap-checking, continuous telemetry or laboratory observations of multi-species groups.

Acknowledgements: I am very grateful to Professor Z. Pucek for inspiring and allowing this study; to A. Arasim, S. Bogdańska, A. Buszko, S. Buszko, J. Hejduk, E. Jancewicz, G. Karbowiak, J. Krawczyk, E. McNeish, M. Rychlik, L. Siemieniuk, M. Szuma, L. Szymura and O. Wood for field and technician assistance; and to the three reviewers for their helpful comments. My English was kindly improved by B. Romanowicz (Univ. Leeds).

\section{References}

Barnard C. J., Brown C. A. J. and Gray-Wallis J. 1983. Time and energy budgets and competition in the common shrew (Sorex araneus L.). Behavioral Ecology and Sociobiology 13: $13-18$.

Bäumler W. 1975. Activity of some small mammals in the field. Acta Theriologica 20: 365377.

Baxter R. M., Goulden E. A. and Meester J. 1979. The activity patterns of some Southern African Crocidura in captivity. Acta Theriologica 24: 61-68.

Buchalczyk A. 1972. Seasonal variations in activity of shrews. Acta Theriologica 17: 221243.

Buchalczyk T. 1964. Daily activity rhythm in rodents under natural conditions. Acta Theriologica 9: 357-362.

Buckner C. H. 1964. Metabolism, food capacity and feeding behaviour in four species of shrews. Canadian Journal of Zoology 42: 259-279.

Cameron G. N., Kincaid W. B. and Carnes B. A. 1979. Experimental species removal: temporal activity patterns of Sigmodon hispidus and Reithrodontomys fulvescens. Journal of Mammalogy 60: 195-197.

Castién E. and Gosálbez J. 1999. Habitat and food preferences in a guild of insectivorous mammals in the Western Pyrenees. Acta Theriologica 44: 1-13.

Cawthorn J. M. 1994. Live trapping study of two syntopic species of Sorex, S. cinereus and S. fumeus, in southwestern Pennsylvania. [In: Advances in the biology of shrews. J. F. Merritt, G. L. Kirkland Jr and R. K. Rose, eds]. Special Publication of Carnegie Museum of Natural History No. 18, Pittsburgh: 39-43. 
Churchfield S. 1982. The influence of temperature on the activity and food consumption of the common shrew. Acta Theriologica 27: 295-304.

Churchfield S. 1984. Dietary separation in three species of shrew inhabiting water-cress beds. Journal of Zoology, London 204: 211-228.

Churchfield S. 1990. The natural history of shrews. Christopher Helm (Publishers) Ltd., Bromley: 1-178.

DeCoursey P. J. 1989. Photoentrainment of circadian rhythms: an ecologist's viewpoint. [In: Circadian clocks and ecology. Hiroshige T. and Honma K., eds]. Hokkaido University Press, Sapporo: 187-206.

DeCoursey P. J. 1990. Circadian photoentrainment in nocturnal mammals - ecological overtones. Biology of Behaviour 15: 213-238.

Ellenbroek F. J. M. and Hamburger J. 1991. Interspecific interactions between the shrews Sorex araneus L. and S. minutus L. (Soricidae, Insectivora) and the use of habitat - a laboratory study. Netherlands Journal of Zoology 41: 32-61.

Faliński J. B. (ed) 1986. Vegetation dynamics in temperate lowland primeval forests. Ecological studies in Białowieża forest. Dr W. Junk Publishers, Dordrecht: 1-537.

Goulden E. A. and Meester J. 1978. Notes on the behaviour of Crocidura and Myosorex (Mammalia: Soricidae) in captivity. Mammalia 42: 197-207.

GraphPAD InStat 1990. GraphPAD InStat version 1.13 software. W. Lampert, Max-PlanckInstitut, 911271S.

Halle S. 2000a. Ecological relevance of daily activity patterns. [In: Activity patterns in small mammals. Ecological Studies, vol. 141. Halle S. and Stenseth N. C., eds]. Springer-Verlag, Berlin, Heidelberg: 67-90.

Halle S. 2000b. Voles - small graminivores with polyphasic patterns. [In: Activity patterns in small mammals. Ecological Studies, vol. 141. Halle S. and Stenseth N. C., eds]. SpringerVerlag, Berlin, Heidelberg: 191-215.

Halle S. and Stenseth N. C. (eds) 2000. Activity patterns in small mammals. Ecological Studies, vol. 141. Springer-Verlag, Berlin, Heidelberg: 1-320.

Hanski I. 1984. Food consumption, assimilation and metabolic rate in six species of shrew (Sorex and Neomys). Annales Zoologici Fennici 21: 157-165.

Hanski I. 1985. What does a shrew do in an energy crisis? [In: Behavioural ecology. Ecological consequences of adaptive behaviour. The 25th Symposium of the British Ecological Society, Reading 1984. Sibly R. M. and Smith R. H., eds]. Blackwell Scientific Publications, Oxford: 247-252. 
Hanski I. 1994. Population biological consequences of body size in Sorex. [In: Advances in the biology of shrews. Merritt J. F., Kirkland G. L. Jr and Rose R. K., eds]. Special Publication of Carnegie Museum of Natural History No. 18, Pittsburgh: 15-26.

Ivanter E. V. and Makarov A. M. 2002. [Circadian activity and movements of the common shrew (Sorex araneus L.). Ekologiya 4: 298-303. [In Russian]

Jánský L. and Hanák V. 1960. Aktivität der Spitzmäuse unter natürlichen Bedingungen. Säugetierkundliche Mitteilungen 8: 55-63.

Karulin B. E., Khylap L. A., Nikitina N. A., Kovalevsky Yu. V., Teslenko K. B. and Albov S. A. 1974. Activity and use of refuges in the common shrew (from observations on animals labelled with radioactive cobalt). Byulleten' Moskovskogo Obshchestva Ispytatelei Prirody, Otdel biologicheskii 79: 65-72. [In Russian with English summary]

Kenagy G. J. 1973. Daily and seasonal patterns of activity and energetics in a heteromyid rodent community. Ecology 54: 1201-1219.

Kotler B. P., Brown J. S. and Subach A. 1993. Mechanisms of species coexitence of optimal foragers - temporal partitioning by two species of sand dune gerbils. Oikos 67: 548-556.

Kronfeld-Schor N. and Dayan T. 1999. The dietary basis for temporal partitioning: food habits of coexisting Acomys species. Oecologia 121: 123-128.

Krushinska N. L. and Pucek Z. 1989. Ethological study of sympatric species of European water shrews. Acta Theriologica 34: 269-285.

Krushinska N. L. and Rychlik L. 1993. Intra- and interspecific antagonistic behaviour in two sympatric species of water shrews: Neomys fodiens and $N$. anomalus. Journal of Ethology 11: $11-21$.

Lardet J. P. 1988. Spatial behaviour and activity patterns of the water shrew, Neomys fodiens in the field. Acta Theriologica 33: 293-303.

Malmquist M. G. 1985. Character displacement and biogeography of the pygmy shrew in northern Europe. Ecology 66: 373-377.

Malmquist M. 1986. Density compensation in allopatric populations of the pygmy shrew Sorex minutus on Gotland and the outer Hebrides - evidence for the effect of interspecific competition. Oecologia 68: 344-346.

Merritt J. F. and Vessey S. H. 2000. Shrews - small insectivores with polyphasic patterns. [In: Activity patterns in small mammals. Ecological Studies, vol. 141. Halle S. and Stenseth N. C., eds]. Springer-Verlag, Berlin, Heidelberg: 235-251.

O'Farrell M. J. 1974. Seasonal activity patterns of rodents in a segebrush community. Journal of Mammalogy 55: 809-823.

Ohdachi S. 1994. Total activity rhythms of three soricine species in Hokkaido. Journal of Mammalogical Society of Japan 19: 89-99. 
Ohdachi S. 1997. Laboratory experiments on spatial use and aggression in three sympatric species of shrews in Hokkaido, Japan. Mammal Study 22: 11-26.

Pernetta J. C. 1977. Population ecology of British shrews in grassland. Acta Theriologica 22: 279-296.

Pianka E. R. 1973. The structure of lizard communities. Annual Review of Ecology and Systematics 4: 53-74.

Priotto J. and Polop J. 1997. Space and time use in syntopic populations of Akodon azarae and Calomys venustus (Rodentia, Muridae). Zeitschrift für Säugetierkunde 62: 30-36.

Rácz G. and Demeter A. 1998. Character displacement in mandible shape and size in two species of water shrews (Neomys, Mammalia: Insectivora). Acta Zoologica Academiae Scientiarum Hungaricae 44: 165-175.

Rychlik L. 1997. Differences in foraging behaviour between water shrews: Neomys anomalus and Neomys fodiens. Acta Theriologica 42: 351-386.

Rychlik L. 2000. Habitat preferences of four sympatric species of shrews. Acta Theriologica 45, Suppl. 1: 173-190.

Rychlik L. 2001. Habitat preferences of water shrews and root vole coexisting along a stream in Białowieża Forest. Säugetierkundliche Informationen, Jena 5: 99-112.

Rychlik L. and Jancewicz E. 2002. Prey size, prey nutrition, and food handling by shrews of different body sizes. Behavioral Ecology 13: 216-223.

Rychlik L. and Ramalhinho M. G. 2005. Habitat preferences of the Mediterranean water shrew Neomys anomalus in Portugal. [In: Advances in the biology of the Soricidae II. J. F. Merritt, S. Churchfield, R. Hutterer and B. I. Sheftel, eds]. Special Publication of Carnegie Museum of Natural History No. 22, Pittsburgh. (in press)

Rychlik L., Ruczyński I., Borowski Z. and Friedrich T. 2004. Space use and competitive interactions in shrews (Insectivora: Soricidae) revealed by radio-telemetry. [In: Contributions to the $5^{\text {th }}$ International Symposium on Physiology, Behaviour and Conservation of Wildlife, Berlin, Germany, 26-29 September 2004. C. Voigt and H. Hofer, eds]. Advances in Ethology 38, Suppl. to Ethology: 172.

Schoener T. W. 1974. Resource partitioning in ecological communities. Science 185: 27-39.

Shillito J. F. 1963. Field observations on the growth, reproduction and activity of a woodland population of the common shrew, Sorex araneus L. Proceedings of the Zoological Society of London 140: 99-114.

SYSTAT 1992. Systat for Windows, version 5.01 software. SYSTAT, Inc., Evanston, IL.

Taylor J. R. E. 1998. Evolution of energetic strategies in shrews. [In: Evolution of shrews. Wójcik J. M. and Wolsan M., eds]. Mammal Research Institute, Polish Academy of Sciences, Białowieża: 309-346. 
Tupikova N. V. 1949. [The diet and nature of circadian activity of shrews from central region of USSR]. Zoologicheskii Zhurnal 28: 561-572. [In Russian]

Voesenek L. A. C. J. and van Bemmel A. C. 1984. Intra and interspecific competition in the water shrew in the Netherlands. Acta Theriologica 29: 297-301.

Vogel P. 1976. Energy consumption of European and African shrews. Acta Theriologica 21: 195-206.

Vogel P. 1980. Metabolic levels and biological strategies in shrews. [In: Comparative physiology: primitive mammals. Schmidt-Nielsen K., Bolis L. and Taylor C. R., eds]. Cambridge University Press, Cambridge: 170-180.

Yalden D. W., Morris P. A. and Harper J. 1973. Studies on the comparative ecology of some French small mammals. Mammalia 37: 257-276.

Yoshino H. and Abe H. 1984. Comparative study on the foraging habits of two species of soricine shrews. Acta Theriologica 29: 35-43.

Ziv Y. and Smallwood J. A. 2000. Gerbils and heteromyids - interspecific competition and the spatio-temporal niche. [In: Activity patterns in small mammals. Ecological Studies, vol. 141. Halle S. and Stenseth N. C., eds]. Springer-Verlag, Berlin, Heidelberg: 159-176.

Zwolak R. and Rychlik L. 2004. Does the reduction of locomotor activity serve as an aggression avoidance mechanism in shrews (Soricidae)? Electronic Journal of Polish Agricultural Universities, Biology 7(2)

http://www.ejpau.media.pl/series/volume7/issue2/biology/art-06.html. 
Table 1. Interspecific similarity of activity curves (revealed by pairwise Pearson correlation: the higher significance of correlation, the higher similarity of curves; values above the diagonal) and interspecific overlaps of temporal niches (below the diagonal) among the four shrew species co-existing in wet habitats of Białowieża Forest.

\begin{tabular}{|c|c|c|c|c|}
\hline & S. minutus & S. araneus & N. anomalus & N. fodiens \\
\hline S. minutus & - & $\begin{array}{c}r_{\mathrm{P}}=0.892 \\
p=0.042 *\end{array}$ & $\begin{array}{c}r_{\mathrm{P}}=0.832 \\
p=0.080 \mathrm{~ns}\end{array}$ & $\begin{array}{c}r_{\mathrm{P}}=0.802 \\
p=0.103 \mathrm{~ns}\end{array}$ \\
\hline S. araneus & $98.36 \%$ & - & $\begin{array}{c}r_{\mathrm{P}}=0.846 \\
p=0.071 \mathrm{~ns}\end{array}$ & $\begin{array}{c}r_{\mathrm{P}}=0.867 \\
p=0.057 \mathrm{~ns}\end{array}$ \\
\hline N. anomalus & $93.34 \%$ & $91.78 \%$ & - & $\begin{array}{c}r_{\mathrm{P}}=0.994 \\
p=0.001 * * *\end{array}$ \\
\hline N. fodiens & $89.34 \%$ & $88.26 \%$ & $99.29 \%$ & - \\
\hline
\end{tabular}




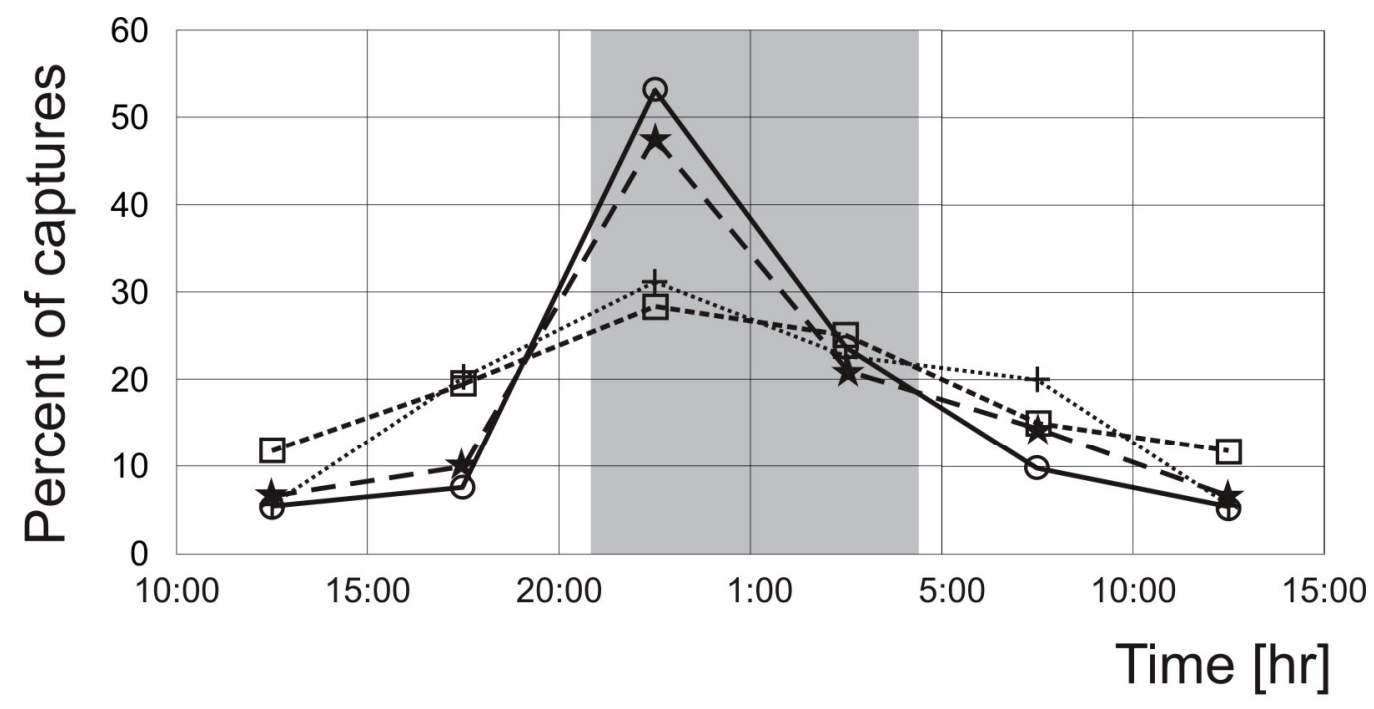

- $\star$ - Neomys anomalus

--曰-- Sorex araneus

- Neomys fodiens

......... Sorex minutus

Fig. 1. Circadian activity of the four shrew species co-existing in wet habitats of Białowieża Forest (June/July). 